\title{
Saccharomyces forkhead protein Fkh1 regulates donor preference during mating-type switching through the recombination enhancer
}

\author{
Kaiming Sun, ${ }^{1}$ Eric Coïc, ${ }^{1}$ Zhiqi Zhou, ${ }^{1}$ Pascal Durrens, ${ }^{2}$ and James E. Haber ${ }^{1,3}$ \\ ${ }^{1}$ Rosenstiel Center and Department of Biology, Brandeis University, Waltham, Massachusetts 02254-9910, USA; ${ }^{2}$ Center of \\ Bioinformatics of Bordeaux, University of Bordeaux 2, 33076 Bordeaux cedex, France
}

\begin{abstract}
Saccharomyces mating-type switching results from replacement by gene conversion of the MAT locus with sequences copied from one of two unexpressed donor loci, HML or HMR. MATa cells recombine with HML $\sim 90 \%$ of the time, whereas MAT $\alpha$ cells choose HMRa $80 \%-90 \%$ of the time. HML preference in MATa is controlled by the cis-acting recombination enhancer (RE) that regulates recombination along the entire left arm of chromosome III. Comparison of RE sequences between S. cerevisiae, S. carlsbergensis, and S. bayanus defines four highly conserved regions (A, B, C, and D) within a 270-bp minimum RE. An adjacent $E$ region enhances RE activity. Multimers of region A, D, or E are sufficient to promote selective use of $H M L$. Regions $A, D$, and $E$ each bind in vivo the transcription activator forkhead proteins Fkh1p and Fkh2p and their associated Ndd1p, although there are no adjacent open reading frames (ORFs). Deletion of FKH1 significantly reduces MATa's use of $H M L$, as does mutation of the Fkh1/Fkh2-binding sites in a multimer of region A. We conclude that Fkh1p regulates MATa donor preference through direct interaction with RE.
\end{abstract}

[Key Words: Saccharomyces cerevisiae; donor preference; recombination enhancer; FKH1; FKH2; mating-type switching]

Received April 4, 2002; revised version accepted June 18, 2002.

Mating-type gene switching in Saccharomyces cerevisiae has provided one of the best-studied examples of DNA double-strand break (DSB)-induced recombination in mitotic cells. Recombination is initiated by cleavage of the MAT locus with the sequence-specific HO endonuclease. The ends of the DSB can recombine with one of two silenced and heterochromatic donor loci, $H M L$ and $H M R$, located near the extremities of the same chromosome (Fig. 1A). Gene conversion occurs without crossing-over, often resulting in the replacement of $M A T-Y a$ or $-\mathrm{Y} \alpha$ sequences that regulate whether cells will be a- or $\alpha$-mating type (Strathern 1989; Haber 1992, $1998 \mathrm{a}, \mathrm{b} ; 2002)$. In most strains of $S$. cerevisiae, $H M L$ carries $\mathrm{Y} \alpha$ sequences $(H M L \alpha)$, whereas $H M R$ carries Ya (HMRa). One of the remarkable aspects of this process is the phenomenon of donor preference, in which MATa cells preferentially recombine with $H M L \alpha$, ensuring that recombination will usually result in a change of mating type; similarly, MAT $\alpha$ cells preferentially select $H M R \mathbf{a}$ (Klar et al. 1982; Weiler and Broach 1992; Wu and Haber

${ }^{3}$ Corresponding author.

E-MAIL haber@brandeis.edu; FAX (781) 736-2405.

Article and publication are at http://www.genesdev.org/cgi/doi/10.1101/ gad.994902.
1995; Wu et al. 1996). Donor selection depends on the location of the sequences but not their content, as MATa cells will preferentially recombine with $H M L$ a even versus $H M R \alpha$ (Weiler and Broach 1992). Moreover, MATa's choice of a left-arm donor occurs even if the entire $H M L$ region is replaced by $H M R$ (Weiler and Broach 1992) or if the donor is placed at other locations along the left arm (Wu and Haber 1995). MAT $\alpha$ cells continue to choose a right-arm donor even if $H M R$ is replaced by $H M L$ sequences, again regardless of whether the donor carries Ya or $\mathrm{Y} \alpha$ (Wu et al. 1996).

The control of donor preference depends on a small cis-acting sequence, the recombination enhancer (RE), which acts as a locus-control region to control recombination along the entire left arm of chromosome III (Wu and Haber 1996). RE lies in a $2.5-\mathrm{kb}$ intergenic region. It is located $\sim 29 \mathrm{~kb}$ from the left end of chromosome III (i.e., $17 \mathrm{~kb}$ centromere-proximal to $H M L$ ) between $K A R 4$ and SPB1 genes, but it retains its ability to influence donor choice even if it is inserted $43 \mathrm{~kb}$ further toward the centromere (G.-F. Richard and J.E. Haber, unpubl.). Deletion of the entire RE region causes a profound change in MATa donor preference, so that $H M L$ is used only $10 \%$ of the time, compared with $85 \%-90 \%$ when $\mathrm{RE}$ is present (Wu and Haber 1996). These studies indi- 
Sun et al.

Figure 1. Mating-type switching at the MATa locus. (A) Expression of $\mathrm{HO}$ endonuclease creates a doublestrand break (DSB) at the $\mathrm{Y} / \mathrm{Z} 1$ border of the MAT locus and initiates repair by using the silent donor $H M L$ and leads to gene conversion. The two donor loci (HML and $H M R)$ are maintained in a transcriptionally inactive chromatin structure. Other shared regions of homology are indicated. The preferential use of $H M L$ donor in MATa cells is regulated by a cis-acting element, recombination enhancer (RE), located $\sim 17 \mathrm{~kb}$ centromereproximal to $H M L$. The positions of $H M L, \mathrm{RE}$, centromere, MAT and $H M R$ are indicated. (B) HMR a is replaced by $H M R \alpha$ modified to carry a point mutation that creates a BamHI site, so that it is possible to distinguish which sequences have been gene converted into the MAT locus. Donor preference is assayed in populations of cells induced to switch from MATa to either MAT $\alpha$ or MAT $\alpha-\mathrm{B}$ (Wu and Haber 1995). MATa cells recombine with $H M L \sim 90 \%$ of the time in the presence of RE; when RE is deleted, MATa cells prefer to choose $H M R \quad 80 \%-90 \%$ of the time.

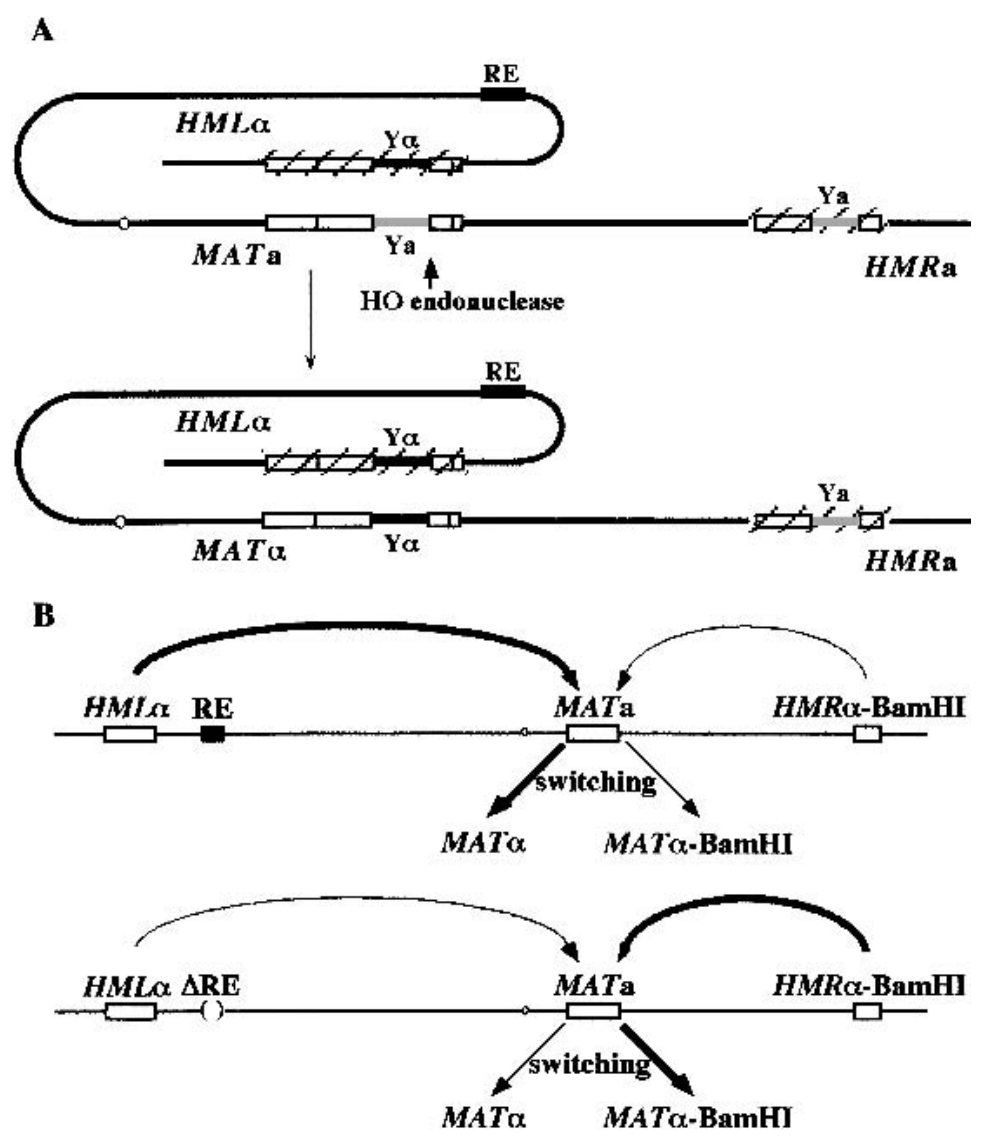

cated that RE acted to make the left arm of chromosome III "hot" for recombination in MATa cells, whereas in $M A T \alpha$ cells the left arm was made unusually inaccessible for recombination (thus allowing $H M R$ to be the preferred donor). These changes in recombination are not accompanied by any change in the mRNA levels of genes along the left arm (Galitski et al. 1999; A.P. Gasch, M.B. Vaze, D. Botstein, P.O. Brown, and J.E. Haber, unpubl.).

Comparison of the RE regions of $S$. cerevisiae and $S$. carlsbergensis allowed us to identify four highly conserved sequences (A, B, C, and D) within a 270-bp region (Wu et al. 1998). Deletion analysis revealed that the A, C, and $\mathrm{D}$ segments were required for activity, so that a minimum enhancer consisting of these three regions increased $H M L$ usage from $10 \%$ without RE to $45 \%$ (Wu et al. 1998). It is likely that an additional region, E (Fig. 2), which shares strong sequence homology with D, especially in $S$. cerevisiae, is also important. That some of these regions function in a redundant fashion is indicated by the finding that a 700-bp region lacking $\mathrm{A}$, but containing B, C, D, and E, was nearly as functional as a 753-bp region containing all five elements $(\mathrm{Wu}$ and Haber 1996). Both regions, D and E, contain repeats of $\mathrm{TTT}(\mathrm{A} / \mathrm{G})$, the only sites in the yeast genome to have such similar-length arrays of this sequence.

How RE works to promote MATa donor preference is not yet understood; to date only one trans-acting mutation, a deletion of $C H L 1$, has been found that alters $M A T$ a donor preference, and in this case the effect is modest (Weiler et al. 1995). We have a better idea how $\mathrm{RE}$ is inactivated in MAT $\alpha$ cells, causing a phenotype of $M A T$ a strain lacking $\mathrm{RE}$; region $\mathrm{C}$ contains a binding site for the Mcm 1-Mat $\alpha 2$ repressor complex that is known to turn off transcription of a set of a-specific genes when the $M A T \alpha$ genes are expressed. In MAT $\alpha$ cells, the RE region is covered with highly positioned nucleosomes that apparently inactivate RE (Weiss and Simpson 1997; Wu et al. 1998). This inactivation is similar to that seen at the promoter of the a-specific STE6 gene (Shimizu et al. 1991; Murphy et al. 1993), although no open reading frame (ORF) is found adjacent to RE. The activation of $\mathrm{RE}$ in MATa cells depends on binding of Mcmlp. In MATa cells, mutation of the Mcml-binding site in RE also leads to the formation of a positioned array of nucleosomes and the loss of RE activity (Wu et al. 1998). At STE6, Mcmlp appears to be a trans-activating transcription factor. The RE does not contain an ORF, but there are several noncoding RNAs (Szeto et al. 1997). Whether Mcmlp is needed for transcription of these noncoding transcripts has not been established; moreover, it should be noted that the minimum RE and synthetic REs that lack these transcribed regions are not seriously impaired in activating $H M L$ in MATa cells (Wu et al. 1998) (results below).

In the present study, we have further characterized the sequences that are critical for RE activity in MATa cells. We have refined the identity of these sequences by sequencing the RE region from $S$. bayanus. We show that 

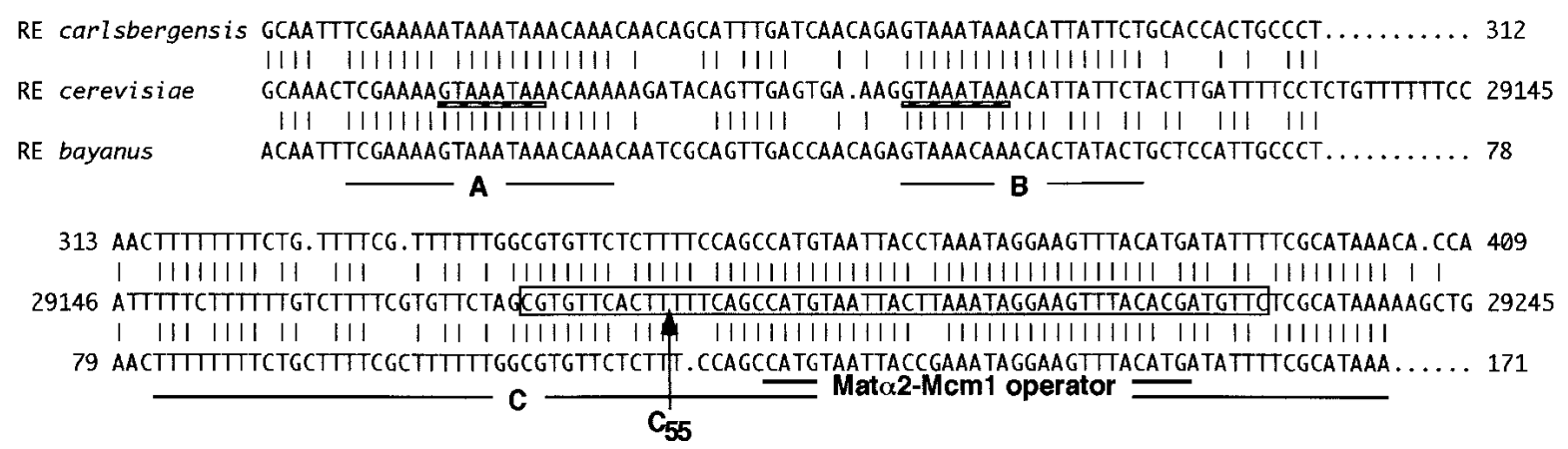

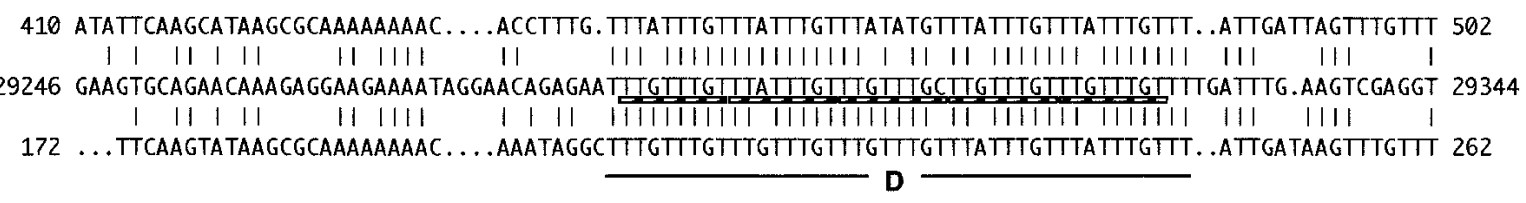

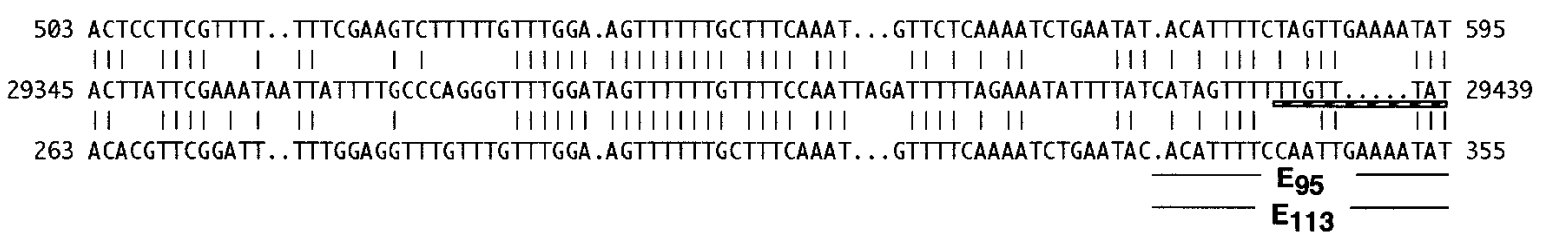

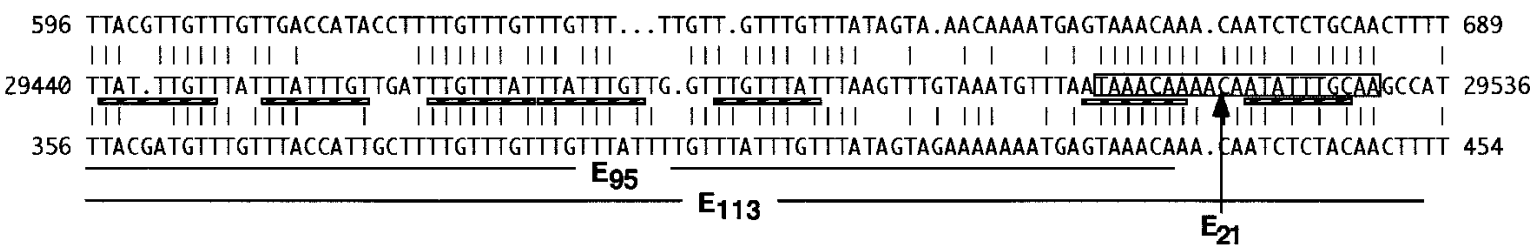

Figure 2. Comparison of RE among three species: Saccharomyces carlsbergensis, S. cerevisiae, and S. bayanus (analyzed in "LASERGENE navigator"). Identical residues in the alignment of the DNA sequences of RE carlsbergensis (top), RE cerevisiae (middle), and RE bayanus (bottom) are indicated by vertical lines. The four most conserved subdomains (designated as A, B, C, and D) and a second near-perfect array of TTT/G/A) repeats (designated as $\mathrm{E}_{113}$ ) are underlined. Region C contains the Mat $\alpha 2-\mathrm{Mcm} 1$ consensus binding site (double underlined). Regions A, B, D, and E contain a total of $15 \mathrm{Fkh} 1 \mathrm{p}$ and Fkh2p consensus binding sites (hatched line). The fragments used to replace the wild-type RE in donor preference assay-designated as $\mathrm{C}_{55}$ (boxed), $\mathrm{E}_{21}$ (boxed), $\mathrm{E}_{95}$ (solid line), and $\mathrm{E}_{113}$ (solid line)—are indicated.

there is substantial redundancy in the $S$. cerevisiae RE region, so that even multimers of $\mathrm{A}, \mathrm{D}$, or $\mathrm{E}$ segment have strong RE activity. Second, we show that Fkh1 and Fkh2 transcription activators bind to region $\mathrm{A}$ in vivo, as well as to regions D and $\mathrm{E}$, and that a $f k h 1 \Delta$ strain has a marked reduction in MATa donor preference. We conclude that, in addition to their key role in regulating expression of a class of cell cycle-regulated genes, forkhead proteins play an important role in the cell cycleindependent activation of the RE.

\section{Results}

In combination with the 270-bp minimum RE, a second region containing TTT(G/A) repeats fully restores $R E$ activation

By comparing the sequences from originally identified 700-bp RE between S. carlsbergensis and S. cerevisiae, a 270-bp minimum RE was defined, containing four highly conserved segments designated A, B, C, and D (Wu et al. 1998) (Fig. 2). When this 270-bp region was then inserted into a chromosome in place of a $1.8 \mathrm{-kb}$ sequence containing $\mathrm{RE}$ and other intergenic sequences between $K A R 4$ and SPB1, this minimum enhancer only retained part of the donor preference activity. A strain carrying a 753-bp RE region selected $H M L \sim 75 \%$ of the time, whereas a strain with 270 -bp RE used $H M L \sim 45 \%$ of the time, which is still significantly above the $10 \%$ level seen when RE is absent (Wu et al. 1998). Further analysis showed that region B is dispensable for MATa's use of $H M L$, but the other three regions were required $(\mathrm{Wu}$ et al. 1998).

We then further refined our examination of RE by including sequences obtained by sequencing the intergenic region between highly homologous KAR4 and SPB1 genes in $S$. bayanus. Three of the four subregions we had previously identified (A, C, and D) were strongly conserved; however, region $\mathrm{B}$ was less conserved among the three species (Fig. 2). We showed that this RE sequence 
was functional by inserting a $3.1-\mathrm{kb}$ sequence containing the $S$. bayanus RE in place of the $S$. cerevisiae RE and showing that $H M L$ usage in MATa cells was $>80 \%$ (data not shown).

A notable feature of $\mathrm{RE}$ region is that it contains many TTT(G/A) repeats. Conserved region D has $10 \mathrm{TTT} / \mathrm{G} / \mathrm{A}$ ) repeats. Region $\mathrm{A}$ and $\mathrm{B}$ also have two or three of such repeats. Among the sequences outside of the 270-bp minimum $\mathrm{RE}$, a less well-conserved segment $\left(\mathrm{E}_{113}\right)$ also contains TTT(G/A) repeats (Fig. 2). The $E_{113}$ region has been shown as a unique nuclease hypersensitive region to micrococcal nuclease digestion flanked by two footprinted regions in S. cerevisiae (Weiss and Simpson 1997).

In the alignment of the DNA sequences from $S$. carlsbergensis, S. cerevisiae, and S. bayanus (Fig. 2), the overall region $\mathrm{E}$ is not conserved among all three species. Interestingly, included in the $\mathrm{E}_{113}$ region is an $18 / 21$ match between $S$. carlsbergensis and $S$. cerevisiae and a 17/21 match between $S$. bayanus and $S$. cerevisiae, centromere-proximal to the less-conserved TTT(G/A) repeats (bp29512-bp29532, designated $\mathrm{E}_{21}$, boxed in Fig. 2).

To investigate whether the other important cis-acting elements other than A, C, and D contribute to the function of RE, a series of deletions were made in a 732-bp RE fragment that has the same activity as the 753-bp RE shown previously (Wu et al. 1998; Fig. 3). To assess donor preference, MATa cells carrying a galactose-inducible $H O$ gene were transferred from YEP-lactate medium to YEP-galactose for $1.5 \mathrm{~h}$ to induce gene conversion of $M A T a$, which can use either $H M L \alpha$ or $H M R \alpha-\mathrm{B}$ as a donor (Wu and Haber 1995). $H M R \alpha-\mathrm{B}$ carries a single basepair mutation that creates a $\mathrm{BamHI}$ site and allows us to distinguish which sequences have been gene converted into the MAT locus (Fig. 1B). As shown in Figure 3, deletions removing the second $\mathrm{TTT}(\mathrm{G} / \mathrm{A})$ repeat-rich region (E) caused a significant reduction in RE activity (Fig. 3 , cf. lanes 12 and 5). A small deletion (bp29505bp29535) including the highly conserved $\mathrm{E}_{21}$ region in a 732-bp RE decreased MATa's use of $H M L$ from $\sim 75 \%$ to $\sim 65 \%$ (Fig. 3, \#12 and \#11). Further deletions in TTT(G/ A) region diminished the activity from $\sim 65 \%$ to $\sim 55 \%$ when at least seven TTTG/A repeats remained (Fig. 3, \#8). Activity fell to $40 \%$ when only three TTT(G/A) repeats were retained (Fig. 3, \#6). This result argues that region $\mathrm{E}$ is an important contributor to overall $\mathrm{RE}$ activity.

\section{Linker sequences between regions $A, C$, and $D$ are dispensable}

To define the active elements within RE more precisely, we ligated together various combinations of the conserved regions, $\mathrm{A}, \mathrm{C}, \mathrm{D}$, and $\mathrm{E}$. In all cases, the constructs were introduced into a $1.8-\mathrm{kb}$ deletion that removed the native RE. A construct containing a 22-bp A region, a 55-bp segment of the $\mathrm{C}$ region including the Mcmlpbinding site (designated $\mathrm{C}_{55}$, in Fig. 2), and a 43-bp D region had approximately the same activity as the entire 270-bp minimum RE (Fig. 4A, KS226). This construct

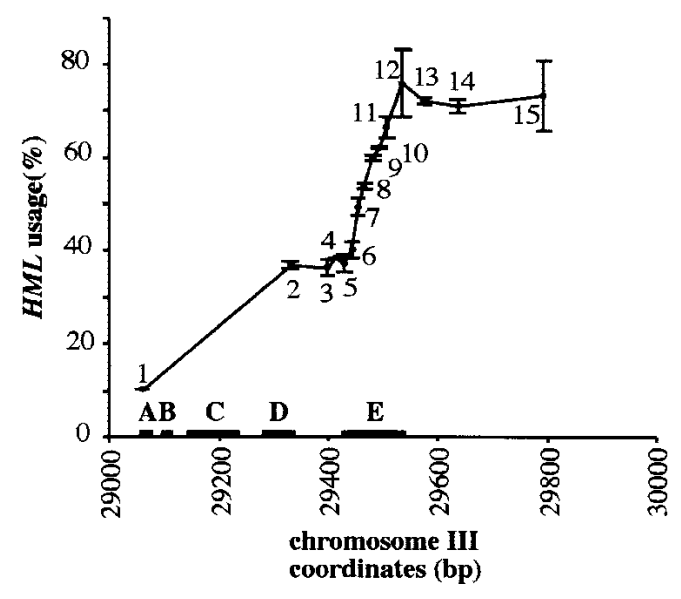

Figure 3. Identification of region $\mathrm{E}$, which, in combination with $\mathrm{A}, \mathrm{B}, \mathrm{C}$, and $\mathrm{D}$, can provide full RE activity in MATa cells through a series of deletions from centromere-proximal end of $\mathrm{RE}$ region. The different $\mathrm{RE}$ fragments were introduced into the chromosome III to replace a $1.8-\mathrm{kb}$ sequence containing RE. The strains used here (XW676, CWu81, KS210, KS209, KS208, KS207, KS206, KS205, KS204, KS203, KS202, KS198, KS199, KS184, and KS185) are indicated as 1-15, respectively. Number 1 is the strain that has no RE fragment inserted into a $1.8-\mathrm{kb}$ deletion. Number 2 carries the chromosome III region from $29059 \mathrm{bp}$ to $29330 \mathrm{bp}$, which was reported previously as the 270-bp RE (Wu et al. 1998). Numbers 3-14 each represent strains that carry a fragment starting from 29059 bp of chromosome III to centromere-proximal end. The numbers of TTT/G/ A) repeats are \#3 (0), \#4 (0), \#5 (0), \#6 (3), \#7 (5), \#8 (7), \#9 (11), \#10 (14), \#11 (16), \#12 (20), \#13 (20), and \#14 (20). Number 15 carries the 732-bp RE starting from 29059 bp to 29790 bp. Donor preference is shown as the percentage of $H M L$ usage in MATa cells. Important region $\mathrm{E}$ is from $\sim 29423$ to $\sim 29535 \mathrm{bp}$ as indicated above.

was inserted in the opposite orientation as the normal $\mathrm{RE}$, but previous studies had shown that RE is orientation independent (Wu and Haber 1996). Thus the regions in between $\mathrm{A}, \mathrm{C}$, and $\mathrm{D}$ are not important for minimum RE function, which therefore resides in these $120 \mathrm{bp}$. This result also means that the exact positioning of these elements on the chromosome is not crucial.

Regions $A, D$, and $E$ function in a redundant fashion and the requirement of $M c m 1$ binding is bypassed in synthetic RES

To determine if there were redundancies among regions A, C, D, and E, we tested the function of multimers of individual subdomains. We found that trimers of $\mathrm{C}_{55}$ alone were unable to activate the use of $H M L$ as a donor; in this case, $H M L$ usage was $<10 \%$ (KS181 in Fig. 4B). Similarly dimers of A, D, or E alone had no activity (data not shown). However, dimers of A, D, or E combined with one $\mathrm{C}_{55}$ domain increased the use of $H M L$ (Fig. 4C, $19.3 \%$ in $\mathrm{KS} 246,32.5 \%$ in $\mathrm{KS} 222$, and $30.0 \%$ in KS339). Again, the orientation and precise position of these additional elements did not seem to be important. A strain 


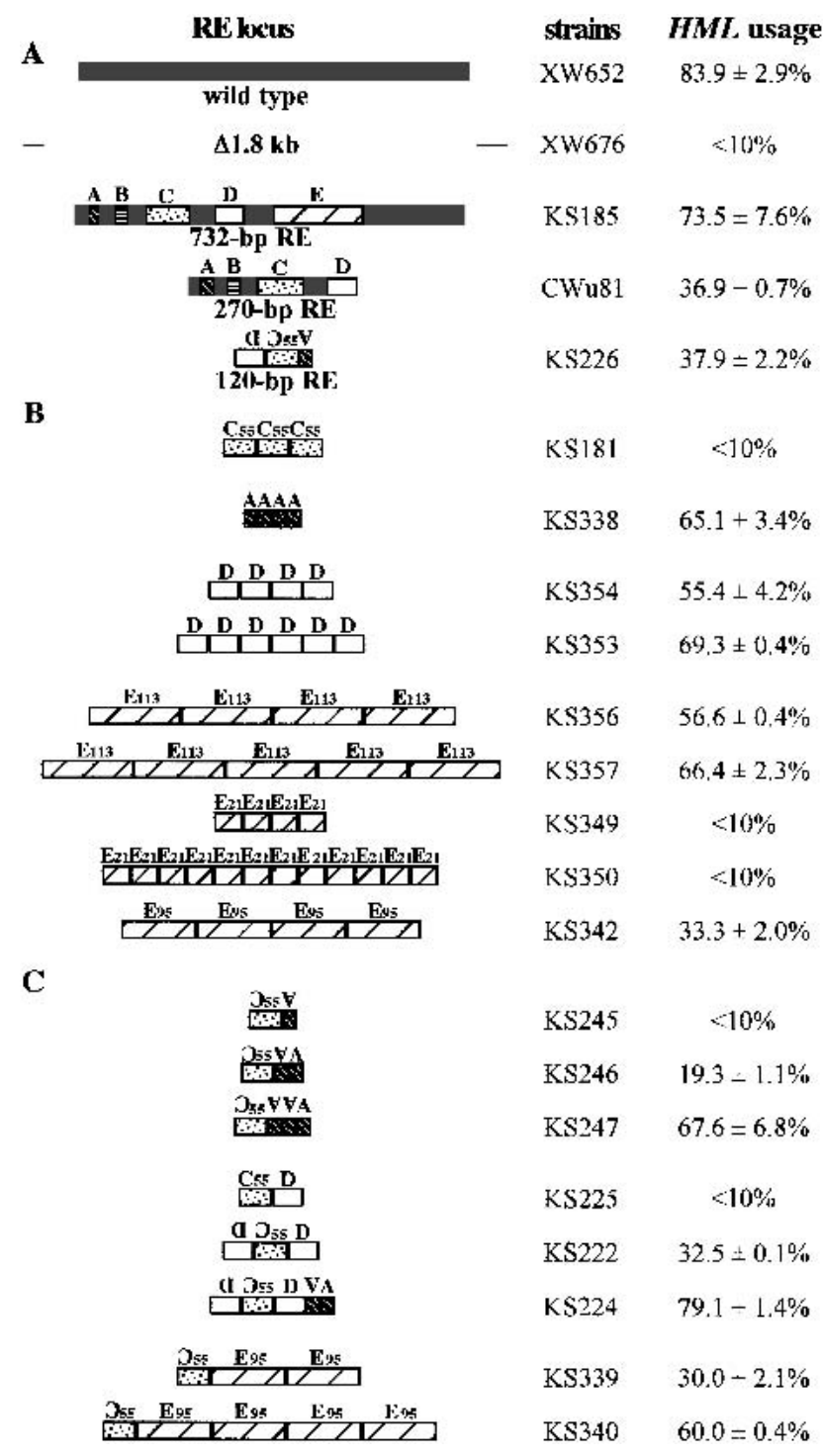

Figure 4. Effect of different combinations of regions A, C, D, and $\mathrm{E}$ on the percentage of $H M L$ usage in MATa cells. The different synthetic RE fragments were introduced into the chromosome III to replace the $1.8 \mathrm{-kb}$ sequence containing RE. $\mathrm{C}_{55}$, $\mathrm{E}_{21}, \mathrm{E}_{95}$, and $\mathrm{E}_{113}$ are indicated in Fig. 2. All other regions, $\mathrm{A}, \mathrm{C}$, and $\mathrm{D}$, used here contain full length of consensus sequences.

with a synthetic $\mathrm{RE}$ consisting of A-A-C ${ }_{55}-\mathrm{D}-\mathrm{D}$ used $H M L$ at nearly wild-type levels (Fig. 4C, 79\% in KS224).

Surprisingly, tetramers of A (KS338), D (KS354), and E (KS356) were able to substantially activate $H M L$ as a donor (50\%-65\% HML usage). Adding more copies of D (KS353) or E (KS357) gave still further increases (66\%$69 \%$ ), approaching the level of activity seen with the native RE (Fig. 4B).

By a similar approach, we found that the conserved $E_{21}$ region lacking TTT(A/G) repeats cannot by itself activate the use of $H M L$ as a donor (Fig. 4B, KS350). In contrast, a tetramer of the TTT(A/G)-containing part of region $\mathrm{E}\left(\mathrm{E}_{95}\right)$ can provide an activation of $H M L$ (Fig. 4B, $33 \%$ in KS342), although not as strongly as the more well-preserved TTT(A/G)-containing D region $(60 \%)$. We conclude that region $\mathrm{A}, \mathrm{D}$, or $\mathrm{E}$ each is sufficient to provide at least some RE function.

In MATa cells, the binding of Mcm $1 \mathrm{p}$ in the intact RE region is required for the activation of $R E$ because of its ability to remove highly positioned nucleosomes that lead to the repression of RE activity (Wu et al. 1998). Here we show that multimers of A, D, or E are each active by themselves and that the requirement for binding of Mcml in the wild-type RE can be bypassed. It is possible that the role of $\mathrm{Mcm} 1 \mathrm{p}$ is to facilitate chromatin reorganization to provide access to the $\mathrm{A}, \mathrm{D}$, and $\mathrm{E}$ sites.

In MAT $\alpha$ cells, the binding of Mat $\alpha 2 / \mathrm{Mcm} 1 \mathrm{p}$ at the RE region was shown to be responsible for the repression of RE because of its ability to organize highly positioned nucleosomes that led to the repression of RE activity (Tanaka et al. 1984; Szeto and Broach 1997; Szeto et al. 1997; Weiss and Simpson 1997; Wu et al. 1998). Previously, we showed that mutations of the Mat $\alpha 2$-binding site removed most of this repression $15 \%$ of $H M L$ usage in wild-type $M A T \alpha$ vs. $55 \%$ in Mat $\alpha 2$-binding site mutant) (Wu et al. 1998). In this study, we replaced the wild-type RE with tetramers of region A in MAT $\alpha$ cells. Here, too, there was no repression caused by Mat $\alpha 2 /$ Mcm 1p. The use of $H M L$ increased from $\leqq 10 \%$ without RE to $50 \%$ (data not shown). Thus, the repression normally seen in RE does not occur when there is no Mat $\alpha 2 \mathrm{p}-\mathrm{Mcm} 1 \mathrm{p}$ binding.

\section{Region A contains a consensus binding site for forkhead transcription factors}

We focused our attention on region A, where four tandem copies gave $65 \%$ HML usage in MATa cells. To determine the binding site for any potential trans-acting factors in this region, a series of deletions was created and then two such truncated region As were joined to $\mathrm{C}_{55}$ and $\mathrm{D}$ to assess donor preference. As shown in Figure $5 \mathrm{~A}$, region A activity was apparently contained within a 15 -bp region, which in this assay had as much activity as the intact A region. This region contains the 13-bp sequence 5'-GTAAATAAACAAA-3' conserved in S. carlsbergensis, S. bayanus, and S. cerevisiae. Deletions of either the left $8 \mathrm{bp}$ or the right $5 \mathrm{bp}$ of this 13-bp region abolished RE activity from $\sim 50 \%$ to $\sim 10 \% \mathrm{HML}$ usage in MATa cells. We tested one TA to GC mutation within this sequence $\left(5^{\prime}\right.$-GTAAAGCAACAAA-3') and found that it also severely impaired MATa's use of $H M L$ when two copies of the mutated A region (Am) were combined with single copies of $\mathrm{C}_{55}$ and D (Fig. 5A, KS251). In contrast, three other 2-bp mutations did not affect MATa's use of $H M L$ (Fig. 5A, see strains KS325, KS326, and KS327).

Having identified a mutation within region A that appears to abolish its function, we used MatInspector V2.2 (Quandt et al. 1995) to search the region A and the entire $\mathrm{RE}$ region for the binding sites of transcription factors. The 13-bp consensus A region was shown to contain a potential binding site $\left(5^{\prime}\right.$-GTAAATAAA- $\left.3^{\prime}\right)$ for the forkhead family of transcription factors (Fig. 5B). Similar pu- 
Sun et al.

A

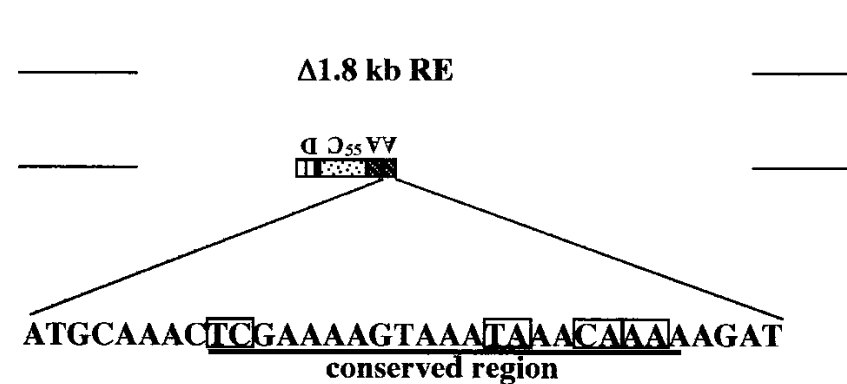

conserved region

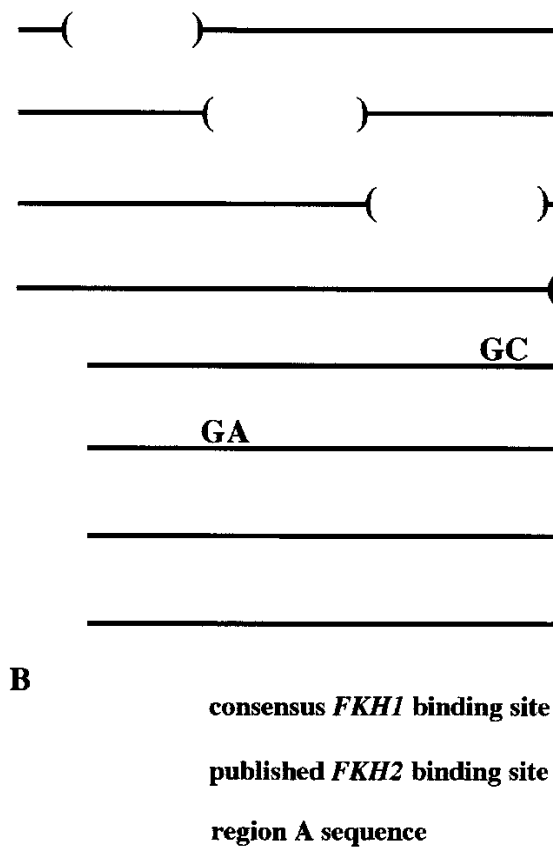

TC strains $H M L$ usage

XW676 <10\%

KS249 $49.9 \pm 0.1 \%$

$\mathrm{KS} 228 \quad 45.9 \pm 3.3 \%$

$\mathrm{KS} 229 \quad 31.2 \pm 0.4 \%$

$\mathrm{KS} 230 \quad 9.8 \pm 0.7 \%$

$\mathrm{KS} 231 \quad 11.2 \pm 5.5 \%$

$\mathrm{KS} 251 \quad 14.6 \pm 0.8 \%$

$\mathrm{KS} 325 \quad 45.9 \pm 2.0 \%$

KS326 $46.8 \pm 2.1 \%$

KS327 $48.1 \pm 8.5 \%$
R YAACAWW

G T A A A Y A A

G T A A A T A A A

Figure 5. Identification of functional region A-binding site. $(A)$ Identification of essential sequences within region $\mathrm{A}$ by introduction of the $\mathrm{A}+\mathrm{A}+\mathrm{C}_{55}+\mathrm{D}$ synthetic REs carrying different deletions or $2 \mathrm{bp}$ mutations on each A into the chromosome III to replace a $1.8-\mathrm{kb}$ sequence containing RE. The 2-bp changes are boxed. The conserved region is underlined. Donor preference is shown as the percentage of $H M L$ usage in MATa cells. (B) Comparison of consensus Fkh1p- and Fkh2p-binding sites reported previously (Zhu et al. 2000) with region A sequence. R: A or G; Y: T or C; W: A or T.

tative forkhead-binding sites were found in regions $\mathrm{B}, \mathrm{D}$, and $\mathrm{E}$ (Fig. 2).

The fkh1 fkh2 double mutant reduces donor preference in MATa cells

In S. cerevisiae, there are four forkhead homologs, FKH1, FKH2, HCM1, and FHL1 (Zhu et al. 1993; Hermann-Le Denmat et al. 1994; Hollenhorst et al. 2000). Among the four members of the forkhead protein family, only Fkh $1 \mathrm{p}$ and Fkh2p share significant sequence similarity $147 \%$ identity overall) between each other outside of the highly conserved forkhead DNA-binding domain. Fkhlp and Fkh2p were shown to activate transcription of the cell-cycle-dependent CLB2 cluster and to affect $H M R$ transcriptional silencing (Hollenhorst et al. 2000, 2001; Koranda et al. 2000; Kumar et al. 2000; Zhu et al. 2000). In addition, FKH1 and FKH2 also have redundant func- tions in preventing pseudohyphal growth (Hollenhorst et al. 2000). On the basis of these observations, we made

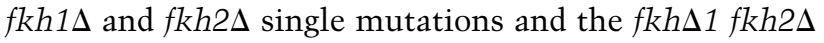
double mutant in different strains containing either wild-type RE or synthetic REs and tested them for donor preference.

In a strain carrying wild-type RE, $H M L$ was used $\sim 81 \%$ of the time (Fig. 6A, lane 1). A fkh2 $2 \Delta$ derivative did not affect donor preference (Fig. 6A, lane 2). However a fkh1s fkh2s double or a fkh1s single mutant reduced $H M L$ usage to $<40 \%$ (Fig. 6A, lanes 3,4).

In strains containing a synthetic RE, the wild-type RE was replaced with different fragments containing either $\mathrm{C}_{55}+3 \times \mathrm{A}(\mathrm{KS} 247$ in Fig. 4B), $4 \times \mathrm{A}(\mathrm{KS} 338$ in Fig. 4B), or $5 \times$ E (KS357 in Fig. 4B). As shown in Figure 6, the strains carrying these synthetic REs used $H M L \sim 65 \%$ to $68 \%$ of the time (Fig. 6, lanes 4,7,9). There was no effect on $H M L$ donor preference in the $f k h 2 \Delta$ derivative (Fig. 6, lane 5), 


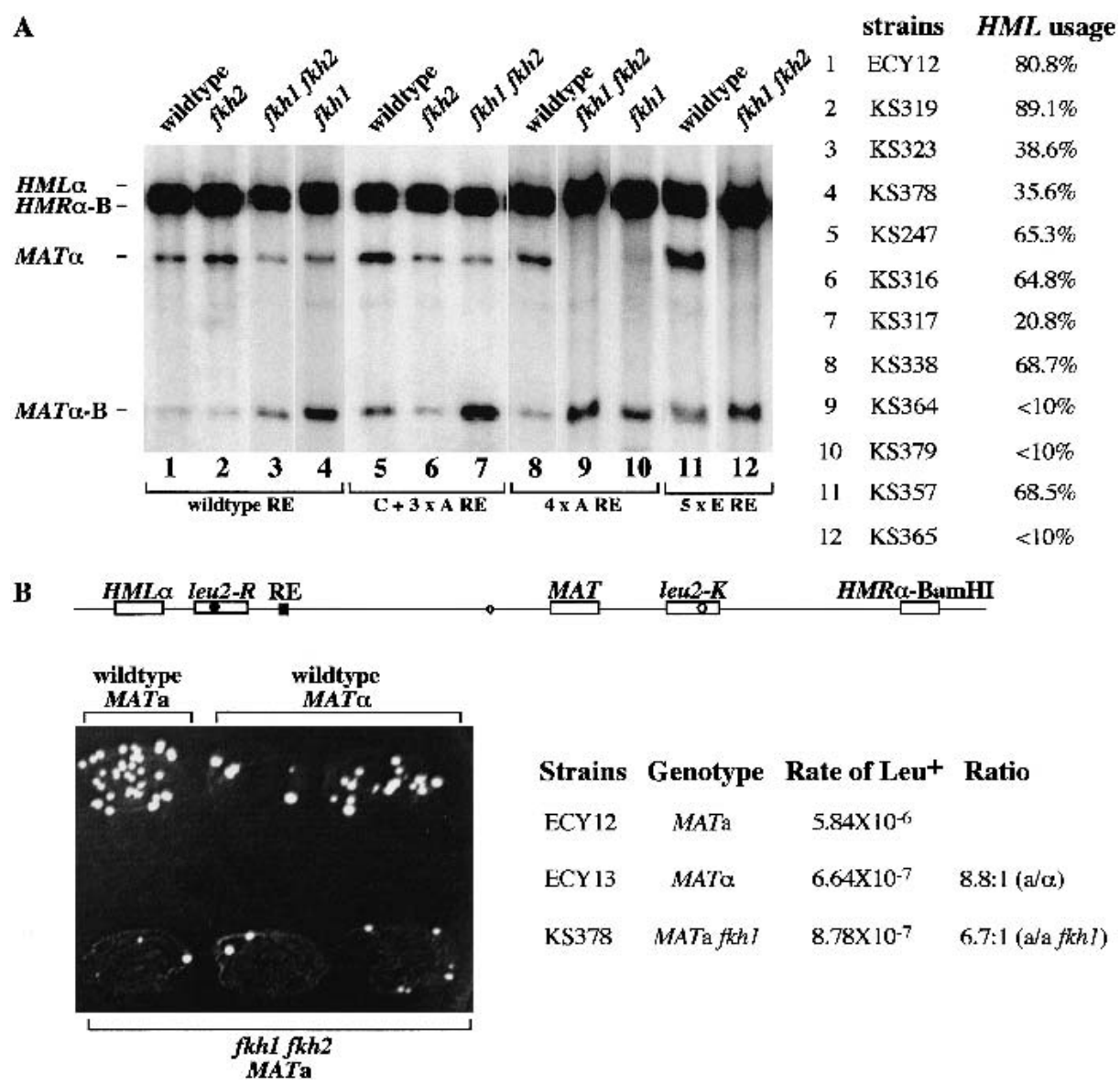

Figure 6. The effects of Fkhlp and Fkh2p on donor preference and leu2 heteroallelic recombination in MATa cells. (A) Analysis of $H M L \alpha$ usage in different strains carrying single or double forkhead deletions in either wild-type $\mathrm{RE}$ or synthetic $\mathrm{RE}$ with $\mathrm{C}+3 \times \mathrm{A}$, $4 \times \mathrm{A}$, and $5 \times \mathrm{E}$. HO-induced switching of MATa to MAT $\alpha$ (from $H M L \alpha$ ) or MAT $\alpha$-Bam (from $H M R \alpha$-Bam) can be assessed densitometrically on a Southern blot of DNA digested with BamHI and HindIII restriction endonucleases. Y $\alpha$-specific probe was used to give rise to four specific bands indicated above. Donor preference is shown as the percentage of $H M L$ usage in MATa cells. (B) Spontaneous recombination between $1 e u 2-R$ inserted at $\mathrm{kb} 22$ of chromosome III and leu2-K located at $\mathrm{kb} 233$ of the right arm of $M A T$ produces Leu ${ }^{+}$ prototrophs. The wild-type MATa and MAT $\alpha$ and mutant $f k h 1 f k h 2 M A T \mathbf{a}$ were patched on a YEPD plate and then replica-plated to synthetic medium lacking leucine. The rate of LEU2 prototroph formation was determined by a fluctuation test (Lea and Coulson 1949).

but there was a significant decrease of $H M L$ donor preference in the $f k h 1 \Delta$ or the $f k h 1 \Delta f k h 2 \Delta$ double mutant strain, so that $H M L$ was only used $<20 \%$ of the time instead of $\sim 65 \%$ (Fig. 6 , lanes $7,9,10,12$ ). To make sure that the fkh mutations do not affect the efficiency of switching, we used the same genomic DNA made from $f k h 1 \Delta f k h 2 \Delta$ (Fig. 6, lane 7) and confirmed that the efficiency of switching (i.e., the repair of the DSB) was very high $(94.6 \%)$, and that (in this independent measurement of donor preference) the use of $H M L$ was $19.9 \%$ (data not shown), in excellent agreement with the measurement of $20.8 \%$ in Figure 6A. Thus, especially in the synthetic REs in which regions $A, D$, and $E$ are not redundant with each other, the effect of deleting FKH1 is profound. The effect of the double $f k h 1 \Delta f k h 2 \Delta$ mutant is similar to that of the single fkh1s mutant, indicating that Fkhlp plays a more important role in regulating donor preference through the RE.
The fkh1 $\Delta$ fkh2 $\Delta$ mutant eliminates mating-type activation of heteroallelic leu2 recombination

It has been shown that $f k h 1 \Delta$ weakly increases the expression of a1 mRNA from the HMR locus when the adjacent I silencing region is deleted and the $\mathrm{E}$ silencer is simplified; however, this change was not seen in a fkh1s fkh2s double mutant (Hollenhorst et al. 2000). To be sure that the changes in donor preference we saw in $f k h 1 \Delta$ or fkh1s fkh2s strains were not attributable to some change in the heterochromatic structure of $H M L$ or $H M R$, we assayed the effect of the forkhead proteins on spontaneous intrachromosomal recombination between two leu2 alleles to produce Leu2 ${ }^{+}$recombinants. In this assay, neither leu2 allele is silenced nor is recombination dependent on $\mathrm{HO}$ endonuclease cleavage. Previously, we showed that a leu2- $R$ allele, replacing $H M L$, recombined with a leu2-K allele, located near MAT, 25-30-fold more 
frequently in MATa cells than in MAT (Wu and Haber 1995). In the present assay, $H M L$ is present and leu2- $R$ is inserted at $\mathrm{kb} 22$ of chromosome III, between $H M L$ and RE (Fig. 6B). In this strain, there is a $>10$-fold increase in the rate of spontaneous $\mathrm{Leu}^{+}$recombinants in MATa cells versus $M A T \alpha$. In the leu2 recombination assay, we found a very similar effect as we did in the direct monitoring of the use of $H M L$ and $H M R$ in the $f k h 1 \Delta$ or $f k h 1 \Delta$ $f k h 2 \Delta$ mutant. As shown in Figure 6B, numbers of Leu ${ }^{+}$ papillae were much lower in the fkh1s fkh2s double mutant than in the wild-type MATa cells, and all the patches had the lower number of $\mathrm{Leu}^{+}$papillae as seen in $M A T \alpha$ cells. We also measured the rate of spontaneous $\mathrm{Leu}^{+}$recombinants by a fluctuation test based on a minimum of seven independent cultures of each strain, initiated from 100 cells and grown to saturation (Lea and Coulson 1949). As shown in Figure 6B, there is approximately a nine-fold difference in the rate of spontaneous $\mathrm{Leu}^{+}$prototroph formation in MATa versus MAT $\alpha$ cells and approximately a seven-fold difference between wildtype MATa cells and fkh1D MATa cells. Thus, we concluded that the changes in donor preference we saw in $f k h 1 \Delta$ or $f k h 1 \Delta f k h 2 \Delta$ strains were not attributable to some change in the heterochromatic structure of $H M L$ or $H M R$. The fkh1s mutant has the same effect on both donor preference in HO-induced MAT switching and the mating-type dependent difference in spontaneous heteroallelic leu2 recombination.

\section{Ndd1p binds to region $A$}

As an alternative way to screen for proteins that bind to region $\mathrm{A}$, we did one-hybrid screening in which one assays the activation of transcription by a GAL4 activation domain fused to another protein domain that can bind to a specific sequence upstream of two reporter genes. Four tandem copies of domain A were ligated together and subcloned upstream of the minimal promoter of both the pHISi-1 and pLacZi reporter plasmids and then integrated into the yeast genome of YM4271 (Materials and Methods). We screened $5 \times 10^{6}$ transformants and isolated 21 positive clones that were $\mathrm{His}^{+}$on 3 -AT containing plates lacking histidine and also showed high $\beta$-galactosidase activity. Among these 21 positive clones, 18 encoded a known transcription factor, Gln3p, which recognizes an AT-rich binding site (GATAAG) (Stanbrough and Magasanik 1996). Two were from the uncharacterized ORF YDR317W. However, neither the deletions of GLN3 and YDR317W nor a double mutant had an effect on donor preference in mating switching (data not shown).

The last candidate was $N D D 1 . N D D 1$ is an essential gene whose function is required during mitosis (Loy et al. 1999). Recently, it has been shown that Nddlp is associated with the CLB2 and SWI5 promoters in chromatin immunoprecipitation (ChIP) assays (Koranda et al. 2000). Its recruitment at these sites depends on $\mathrm{Mcm} 1 \mathrm{p}$ and on both Fkh2p and Fkh1p. Because NDD1 is essential, we could not assay directly its role in donor prefer- ence, but we could obtain evidence of its participation by ChIP assays.

\section{Fkh1p, Fkh2p, and Ndd1p bind to the RE region in vivo}

If the consensus Fkh1p- and Fkh2p-binding sites represented bona fide Fkh-binding sites and Nddlp can interact with region $\mathrm{A}$ in a one-hybrid assay, then the RE region should be enriched in a protein-DNA fraction prepared by ChIP with antibodies against Fkh1p, Fkh2p, or Nddlp. Previous studies of enrichment of the CLB2cluster promoter by ChIP experiments showed that both Fkh1p and Fkh2p bound to CLB2-cluster promoters, although generally Fkh2p bound more efficiently than Fkh1p (Koranda et al. 2000; Hollenhorst et al. 2001). Interestingly, some CLB2-promoters without Mcm1-binding sites or with a mutant Mcmlp-binding site were occupied equally well or more efficiently by Fkh1 (Hollenhorst et al. 2001). Moreover, Ndd1p was also associated with CLB2 and SWI5 promoters in ChIP assays (Koranda et al. 2000).

Yeast cells harboring integrated FKH1-3xHA, FKH2$3 \times H A$ or NDD1-6xHA genes (Materials and Methods) and wild-type cells containing untagged version of these genes were used in ChIP experiments with an antibody specific for the hemagglutinin epitope $(\alpha-\mathrm{HA})$. To test whether Ndd1, Fkh1p, and/or Fkh2p bound to the RE region in vivo, a 500-bp wild-type $\mathrm{RE}$ region was analyzed by ChIP. As shown in Figure 7A, Fkh1p, Fkh2p, and Nddlp bound to the RE region, although to different extents. Unlike the CLB2-cluster promoter region (Hollenhorst et al. 2001), the signal generated by FKH1$3 \times H A$ was much stronger than the signal generated by FKH2-3xHA, although there is a Mcmlp-binding site inside the RE region. The assay did not allow a precise determination of the binding stoichiometry, but it indicated that Fkh1p may have a more important role than Fkh2p in controlling RE activity.

In $M A T \alpha$ cells, RE is covered with highly positioned nucleosomes that lead to the repression of RE activity; whereas the RE chromatin is less organized in MATa cells (Weiss and Simpson 1997). Our results clearly indicated that Fkhlp can be recruited to RE region in MATa cells. To ask whether Fkhlp can also be recruited to the $\mathrm{RE}$ in MAT $\alpha$ cells, MATa cells carrying FKH1-3xHA were switched to $M A T \alpha$ by introducing a plasmid containing GAL-HO. As shown in Figure $7 \mathrm{~B}$, unlike what we saw in MATa cells, Fkhlp was not recruited to the RE region in the wild-type $M A T \alpha$ cells. This result indicates that Fkhlp can only be recruited to the less-organized RE chromatin found in MATa cells.

To show that the recruitment of Fkh1p and Fkh2p to the RE region are the result of their direct interactions with the putative forkhead-binding sites and Nddlp is recruited to the same regions as forkhead proteins are, we replaced wild-type $\mathrm{RE}$ with synthetic REs carrying $4 \times \mathrm{A}, 6 \times \mathrm{D}$, or $5 \times \mathrm{E}$ and then performed ChIP using the same antibody. As shown in Figure $7 \mathrm{C}$ and D, Fkh1p, Fkh2p, and Ndd1p can be recruited to the $4 \times A, 6 \times D$, 
A

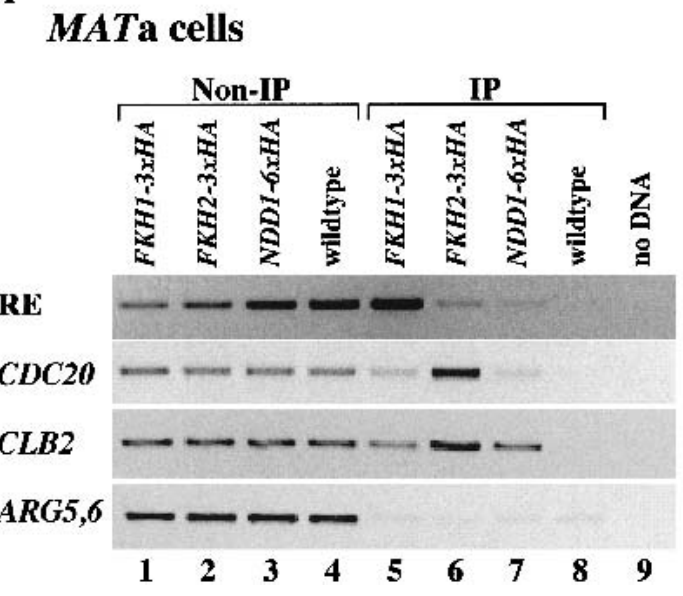

C

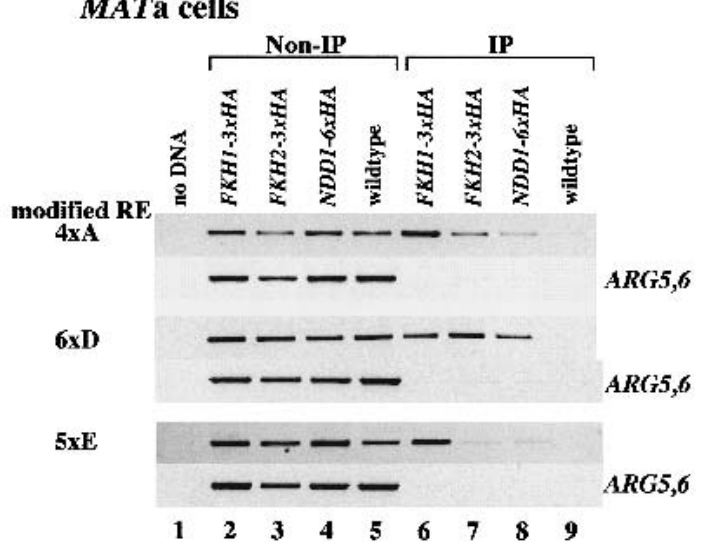

B

\section{$M A T \alpha$ cells}

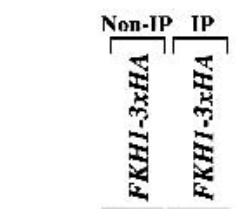

RE

$C L B 2=$

$$
12
$$

D

\section{MATa cells}

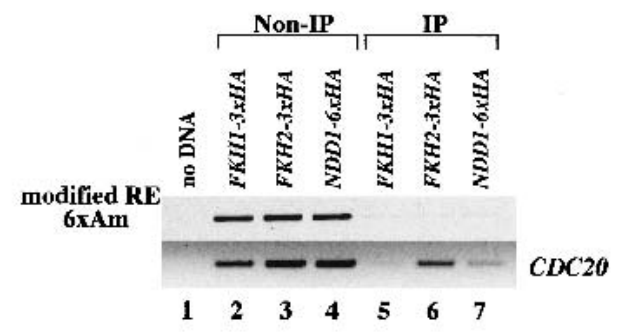

Figure 7. Fkh1p, Fkh2p, and Ndd1p are recruited to the RE in vivo. $(A, B)$ Chromatin immunoprecipitation (ChIP) assays with a different pair of primers that can specifically amplify the wild-type RE region, the promoter regions of CDC20 and CLB2 (positive controls), and the coding region of $A R G 5,6$ (negative control). Strains used in this assay are CFY480 $(A$, lanes 1,5$)$ and CFY854 $(A, l a n e s$ 2,6) (Hollenhorst et al. 2000), 155 (A, lanes 3,7) (Koranda et al. 2000), W303 (A, lanes 4,8), and KS369 (MAT $\alpha$; $B$, lanes 1,2). (C,D) ChIP assays with pairs of primers that can specifically amplify either the modified RE region, the promoter of $C D C 20$ (positive controls), or the coding region of $A R G 5,6$ (negative control). The wild-type RE is replaced by either four copies of region $\mathrm{A}$, six copies of $\mathrm{D}$, five copies of $\mathrm{E}$, or six copies of mutant region A, indicated as $4 \times \mathrm{A}, 6 \times \mathrm{D}, 5 \times \mathrm{E}$, or $6 \times \mathrm{Am}$ at left. Controls that have fragments amplified from $A R G 5,6$ coding region and CDC20 promoter are indicated at right. All strains used here are MATa. Strains used in this assay are $\mathrm{KS} 358(4 \times \mathrm{A}), \mathrm{KS} 359(6 \times \mathrm{D})$, and KS360 $(5 \times \mathrm{E})(C$, lanes 2,6); KS370 $(4 \times \mathrm{A}), \mathrm{KS} 371(6 \times \mathrm{D})$, and KS372 $(5 \times \mathrm{E})(C$, lanes 3,7$) ; \mathrm{KS} 374$ $(4 \times \mathrm{A}), \mathrm{KS} 375(6 \times \mathrm{D})$, and KS376 $(5 \times \mathrm{E})(C$, lanes 4,8); KS361 $(4 \times \mathrm{A}), 362(6 \times \mathrm{D})$, and $363(5 \times \mathrm{E})(C$, lanes 5,9); KS365 $(6 \times \mathrm{Am})(D$, lanes 2,5); KS373 (6× Am) $(D$, lanes 3,6); and $\operatorname{KS} 377(6 \times \mathrm{Am})(D$, lanes 4,7).

and $5 \times \mathrm{E}$, where the consensus forkhead protein-binding sites are present. In contrast, when we inserted six copies of mutant region Am (a TA to GC mutation within forkhead protein-binding site, see KS251 in Fig. 5A) into a 1.8-kb deletion that removed the native RE, Fkh1, Fkh2, and Ndd 1 were not recruited to the $6 \times$ Am region. Thus, the consensus Fkh1p- and Fkh2p-binding sites identified within the RE region represents bona fide Fkh-binding sites. Nddlp can also be recruited to the same region as are forkhead proteins.

\section{Discussion}

We have investigated the manner in which the RE acts to control donor preference during mating-type switching in MATa cells and made several important findings. First, the RE consists of several redundant domains whose exact spacing and orientation is surprisingly flexible. Second, multimers of region A, D, or E are sufficient to promote selective use of $H M L$. Third, activation of $H M L$ donor preference does not require the presence of a Mcm1p-binding site. Finally, we have showed that the transcription regulator Fkhlp plays an important role in the activation of RE in MATa cells, in a region where there are no transcribed genes.

Our previous characterization of RE focused on the C domain in which there is a Mcmlp-Mat $\alpha 2$-binding site. It has been shown that Mcm1p-Mat $\alpha 2$ is responsible for the repression of RE because of its ability to organize highly positioned nucleosomes that lead to the repres- 
sion of RE activity in MAT $\alpha$ cells (Weiss and Simpson 1997; Wu et al. 1998). In MATa cells, the binding of $\mathrm{Mcm} 1 \mathrm{p}$, in the context of the complete RE, is required to activate donor preference (Wu et al. 1998). However, the $\mathrm{C}$ region is not essential for the activation of $H M L$ usage in synthetic REs, because multimers of $4 \times \mathrm{A}$ regions, as well as $4 \times \mathrm{D}$ or $4 \times \mathrm{E}$ regions, lacking a Mcmlp-binding site are nearly as active as the entire RE region. We believe that the role of $\mathrm{Mcm} 1$ is to facilitate the removal of the highly positioned nucleosomes so that other factors can then be recruited to the RE and activate the RE. However, the possibility that Mcmlp could be recruited to the synthetic REs directly by binding to the Fkh2 protein (Hollenhorst et al. 2001) cannot be excluded, although fhk $2 \Delta$ did not affect donor preference.

The $\mathrm{C}$ region and its $\mathrm{Mcm} 1 \mathrm{p}-\mathrm{Mat} \alpha 2 \mathrm{p}$-binding site do seem to be essential for the repression of RE in MAT $\alpha$ cells. The absence of a Mcmlp-Mat $\alpha 2 \mathrm{p}$ site in the $4 \times \mathrm{A}$ construct leads to constitutive RE activity in $M A T \alpha$ cells, although the lower usage of $H M L$ in $M A T \alpha$ cells $(50 \%)$ versus MATa $(66 \%)$ indicates the possibility of a

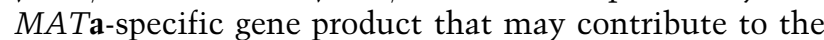
full activation of RE in MATa cells. This difference between MATa and MAT $\alpha$ was previously seen in an intact $\mathrm{RE}$ in which the two Mat $\alpha 2$-binding sites were mutated (Wu et al. 1998).

From the various arrangements of A, C, D, and E domains that activate $H M L$ usage, it is clear that the spacing and orientation of these regions are not critical for RE activity. What seems to be common to all of the different active arrangements of sequences is the presence of multiple sites where either Fkh1p or Fkh2p can bind (Fig. 2). Consistent with this observation is the fact that the $f k h 1 \Delta$ single mutant or the $f k h 1 \Delta f k h 2 \Delta$ double mutant show reduced $H M L$ usage in MATa cells. This is especially evident in the $4 \times \mathrm{A}$ or $5 \times \mathrm{E}$ constructs in which donor preference is reduced from $\sim 65 \%$ to $<10 \%$. However, donor preference is not completely abolished when FKH1 and FKH2 are deleted in a strain carrying an unmodified RE (compare KS323 in Fig. 6A to the complete absence of RE, XW676, in Fig. 3: HML was used $~ 39 \%$ vs. $10 \%)$. The residual RE activity indicates that additional proteins contribute to RE function, probably interacting with other sequences.

The Fkh1p and Fkh2p proteins have been best understood in their role in activating transcription of the $C L B 2$-cluster of cell cycle-regulated genes including CLB2 and SWI5 in the G2 phase of the cell cycle (Hollenhorst et al. 2000, 2001; Kumar et al. 2000; Pic et al. 2000; Zhu et al. 2000). A third protein, Nddlp, is apparently recruited to these promoters by the Fkh proteins, but Nddlp must have additional functions, as it is an essential protein, whereas even $f k h 1 \Delta f k h 2 \Delta$ is viable.

We have shown by ChIP that RE and even simple multimers of A, D, or E regions bind Fkh1p, Fkh2p, and Nddlp. This can occur even in the absence of a Mcmlpbinding site, as in the case of $4 \times \mathrm{A}$, whereas in CLB2 cluster promoters, the recruitment of Fkh2p appears to require the binding of $\mathrm{Mcm} 1 \mathrm{p}$ (Hollenhorst et al. 2001). We cannot rule out that Fkh2p is able to recruit Mcm 1p to promoters that lack Mcmlp-binding sites (Hollenhorst et al. 2001). In many other respects, the action of the Fkh proteins appears to be quite different from their role in CLB2-cluster promoters. First, RE activation does not seem to depend on transcription. In the region including region E, Szeto et al. did find a weak transcript that does not appear to encode a protein (Szeto et al. 1997); however, RE activity does not depend on these sequences because they were absent in the minimum enhancer ( $\mathrm{Wu}$ et al. 1998). This is most evident in the case of the multimers such as $4 \times \mathrm{A}$, each unit of which is only $22 \mathrm{bp}$.

It should be noted that the role of Fkh proteins, in combination with Mcmlp and Nddlp, is to activate the transcripts of CLB2-cluster in G2. Donor preference is not significantly different at different phases of the cell cycle (Wu et al. 1997); indeed, normal MAT switching occurs in G1 cells. Recently, it has been shown that Fkh1 and Fkh2 are also associated with genes expressed in $\mathrm{G} 1$ and $\mathrm{S}$ phase, whereas the binding of $\mathrm{Mcml}$ could not be detected (Simon et al. 2001). It seems clear that the way the Fkh proteins and Nddlp act in donor preference is significantly different from their role at G2regulated promoters.

Despite our progress in delineating the cis-acting domains and some of the key proteins that combine to create RE activity, we still do not know how RE acts to alter the ability of the entire left arm of chromosome III to recombine with the HO-cut $M A T$ locus. Our previous results indicated that in MAT $\alpha$ cells, the entire left arm is inaccessible for recombination (Wu et al. 1996). We imagine that there must be additional sites along this chromosome arm that serve to alter (perhaps immobilize) the left arm to prevent its participation in recombination, but without impairing transcription, both in $M A T \alpha$ cells in which RE is repressed and in MATa cells when RE is deleted. The forkhead proteins and Nddlp bound to RE may then interact with these repressive sites, thus liberating the left arm for recombination.

\section{Materials and methods}

\section{Strains}

All strains used for donor preference experiments were derivatives of DBY745 (ho MATa ade1-100 ura3-53 leu2-3,112). Strains used to monitor MATa donor preference carry $H M R \alpha-\mathrm{B}$, containing a single base-pair mutation that creates the BamHI site (Wu and Haber 1995). They also carry a galactose-inducible $H O$ endonuclease gene integrated at the ADE3 locus (Sandell and Zakian 1993).

All strains used in ChIP were derivatives of W303 provided by C. Fox and G. Ammerer.

All yeast transformations were performed by one-step transformation (Chen et al. 1992) or high-efficiency method (Gietz et al. 1995, 1997). All the disruptions were verified by Southern blot analysis. To disrupt $F K H 1$, a PCR fragment was amplified from the strain that has $\Delta f k h 1:: K A N$ (Record \#32290) obtained from ResGen. To introduce subfragments into a deletion of the $\mathrm{RE}$, a plasmid pKS58 was constructed from pCWU155 (described previously; Wu et al. 1998) except two more unique sites, BamHI and PmlI, were introduced adjacent to Sall. De- 
tails of other specific strain constructions are available on request. The selections of introduction of subfragments into a deletion of the RE were performed as described (Wu and Haber 1996).

\section{Identification of the RE in $\mathrm{S}$. bayanus}

An $S$. bayanus clone containing genes homologous to KAR4 and SPB1 of S. cerevisiae was obtained as part of the study of the evolution of hemiascomycetes (Bon et al. 2000). The S. bayanus DNA was inserted into plasmid pBAM3 in Escherichia coli strain DH10B (as described in Bon et al. 2000). The intervening region was sequenced and aligned with RE regions from $S$. cerevisiae and S. carlsbergensis (Wu et al. 1998). A 3.1-kb fragment containing the conserved $S$. bayanus sequences was inserted in place of the $1.8-\mathrm{kb}$ deletion of $S$. cerevisiae RE, as described previously for testing the $S$. carlsbergensis RE (Wu et al. 1998). The S. bayanus sequence has the GenBank accession no. AY123283.

\section{Analysis of donor preference}

The measurement of donor preference was described previously

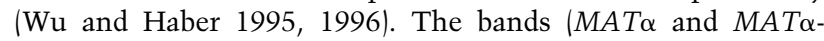
BamHI) corresponding to the use of $H M L$ and $H M R$ were quantified using ImageQuant V1.2 (Molecular Dynamics). In some experiments, YEP-raffinose was used instead of YEP-lactate medium.

\section{One-hybrid screen}

The yeast MATCHMAKER one-hybrid system was purchased from CLONTECH. The screening was essentially performed as recommended by the manufacturer. The $S$. cerevisiae genomic library is provided by Philip James (James et al. 1996). Four tandem copies of $22 \mathrm{bp}$ of wild-type region A were inserted into the polylinker of two plasmids, pHISi-1 and placZi, just upstream of the minimal promoter of HIS3 and lacZ genes to generate pKS133b and pKS132-2. Four tandem copies of $22 \mathrm{bp}$ of nonbinding mutant region A (TA-GC, see KS251 in Fig. 5A) were also inserted into the polylinker of pHISi-1 at the same location to generate pKS165. A wild-type dual reporter yeast strain (KS257) was constructed by integrating pKS133b and pKS132-2 into the genome, and a nonbinding mutant reporter strain (KS259) was also constructed by integrating pKS165 into the genome. Both strains grew poorly on SD (-histidine) +15 $\mathrm{mM}$ 3-aminotriazole (3-AT) and not at all on SD (-histidine) + $45 \mathrm{mM}$ 3-AT plates. The yeast transformation was performed as described by Gietz et al. (1997).

\section{ChIP and analysis of immunoprecipitated DNA}

ChIPs were performed as described previously (Strahl-Bolsinger et al. 1997) with some modifications. The cross-linking time was $10 \mathrm{~min}$ instead of $15 \mathrm{~min}$. Breakage was performed in 500 $\mu \mathrm{L}$ of lysis buffer that contained $1 \mathrm{mM}$ PMSF, $1 \mathrm{mM}$ Benzamidine, and $1 \mathrm{mg} / \mathrm{mL}$ of Bacitracin. The extract was sonicated for a total of $60 \mathrm{sec}$ (resulting in an average DNA size of $500 \mathrm{bp}-1$ $\mathrm{kb})$, clarified by centrifugation, and subjected to immunoprecipitation with anti-HA monoclonal antibody (12CA5, Roche) and protein G-Agarose beads (Roche).

PCR reactions were performed in $50 \mu \mathrm{L}$ volume with one fifth of the immunoprecipitated material or one fiftieth of the non- immunoprecipitated material and serial two-fold dilutions thereof as templates. Hotstar Taq polymerase (Qiagen) was used in $1 \mathrm{X}$ manufacturer's buffer supplemented with $2.5 \mathrm{mM} \mathrm{MgCl}$, $200 \mu \mathrm{M}$ each $\mathrm{dNTP}$, and $500 \mathrm{nM}$ or $1 \mu \mathrm{M}$ of each primer. Typically, 25-30 cycles of amplification were performed. The following primers were used to amplify the RE region: SUN575, 5'-CGCGGATCCAAACTCGAAAAGTAAATA-3', and Wu027, 5'-ACGCTCGAGCCCGGGCTTGCAAATATTGT-3'; SUN540, 5'-CTTGTCGACATAAATCCTTGCTTAGC-3', and P-MAB09, 5'-CAATACCTTCTTGAACCATTTCCC-3'; CDC20 promoter region: SUN844, 5'-ACGTTAGTTGAACTTGAATTCCG-3', and SUN845, 5'-AAGGTGATAAATTCTTTGCCTGC-3'; CLB2 promoter region: SUN842, 5'-GACAGATTTTATTCCAAAT GCGG-3', and SUN 843, 5'-CGCTTTTCAGAAGTATCAA TTCG-3'; ARG5,6 coding region: ARG5,6 p1, 5'-CAAGGATC CAGCAAAGTTGGGTGAAGTATGGTA-3', and ARG5,6 p2, 5'-GAAGGATCCAAATTTGTCTAGTGTGGGAACG-3' .

\section{Acknowledgments}

We are grateful to Catherine Fox and Gustav Ammerer for providing us strains, Philip James for providing the yeast genomic library, Ranjan Sen for advice and critically reading the manuscript, Cherry Wu for her early work on mutations of region A, and Neal Sugawara for his invaluable technical advice. This work was supported by the National Institutes of Health (grant GM20056). E.C. was supported in part by a grant from 1'Association pour la Recherche sur le Cancer.

The publication costs of this article were defrayed in part by payment of page charges. This article must therefore be hereby marked "advertisement" in accordance with 18 USC section 1734 solely to indicate this fact.

\section{References}

Bon, E., Neuveglise, C., Casaregola, S., Artiguenave, F., Wincker, P., Aigle, M., and Durrens, P. 2000. Genomic exploration of the hemiascomycetous yeasts: 5. Saccharomyces bayanus var. uvarum. FEBS Lett. 487: 37-41.

Chen, D.C., Yang, B.C., and Kuo, T.T. 1992. One-step transformation of yeast in stationary phase. Curr. Genet. 21: 83-84.

Galitski, T., Saldanha, A.J., Styles, C.A., Lander, E.S., and Fink, G.R. 1999. Ploidy regulation of gene expression. Science 285: 251-254.

Gietz, R.D., Schiestl, R.H., Willems, A.R., and Woods, R.A. 1995. Studies on the transformation of intact yeast cells by the LiAc/SS-DNA/PEG procedure. Yeast 11: 355-360.

Gietz, R.D., Triggs-Raine, B., Robbins, A., Graham, K.C., and Woods, R.A. 1997. Identification of proteins that interact with a protein of interest: Applications of the yeast twohybrid system. Mol. Cell Biochem. 172: 67-79.

Haber, J.E. 1992. Mating-type gene switching in Saccharomyces cerevisiae. Trends Genet. 8: 446-452.

1998a. A locus control region regulates yeast recombination. Trends Genet. 14: 317-321.

—. 1998b. Mating-type gene switching in Saccharomyces cerevisiae. Annu. Rev. Genet. 32: 561-599.

- 2002. Switching of Saccharomyces cerevisiae matingtype genes. In Mobile DNA II Craig, N.L., Craigie, R., and Gellert, M., eds. pp. 927-951. ASM Press, Washington, D.C.

Hermann-Le Denmat, S., Werner, M., Sentenac, A., and Thuriaux, P. 1994. Suppression of yeast RNA polymerase III mutations by FHL1, a gene coding for a fork head protein involved in rRNA processing. Mol. Cell. Biol. 14: 2905-2913. 
Hollenhorst, P.C., Bose, M.E., Mielke, M.R., Muller, U., and Fox, C.A. 2000. Forkhead genes in transcriptional silencing, cell morphology and the cell cycle. Overlapping and distinct functions for FKH1 and FKH2 in Saccharomyces cerevisiae. Genetics 154: 1533-1548.

Hollenhorst, P.C., Pietz, G., and Fox, C.A. 2001. Mechanisms controlling differential promoter-occupancy by the yeast forkhead proteins Fkh1p and Fkh2p: Implications for regulating the cell cycle and differentiation. Genes \& Dev. 15: 2445-2456.

James, P., Halladay, J., and Craig, E.A. 1996. Genomic libraries and a host strain designed for highly efficient two- hybrid selection in yeast. Genetics 144: 1425-1436.

Klar, A.J., Hicks, J.B., and Strathern, J.N. 1982. Directionality of yeast mating-type interconversion. Cell 28: 551-561.

Koranda, M., Schleiffer, A., Endler, L., and Ammerer, G. 2000. Forkhead-like transcription factors recruit Ndd1 to the chromatin of G2/M-specific promoters. Nature 406: 94-98.

Kumar, R., Reynolds, D.M., Shevchenko, A., Goldstone, S.D., and Dalton, S. 2000. Forkhead transcription factors, Fkhlp and Fkh2p, collaborate with Mcm1p to control transcription required for M-phase. Curr. Biol. 10: 896-906.

Lea, D.E. and Coulson, C.A. 1949. The distribution of numbers of mutants in bacterial populations. J. Genet. 49: 264-285.

Loy, C.J., Lydall, D., and Surana, U. 1999. NDD1, a high-dosage suppressor of cdc28-1N, is essential for expression of a subset of late-S-phase-specific genes in Saccharomyces cerevisiae. Mol. Cell. Biol. 19: 3312-3327.

Murphy, M.R., Shimizu, M., Roth, S.Y., Dranginis, A.M., and Simpson, R.T. 1993. DNA-protein interactions at the $S$. cerevisiae alpha 2 operator in vivo. Nucleic Acids Res. 21: 3295-3300.

Pic, A., Lim, F.L., Ross, S.J., Veal, E.A., Johnson, A.L., Sultan, M.R., West, A.G., Johnston, L.H., Sharrocks, A.D., and Morgan, B.A. 2000. The forkhead protein Fkh2 is a component of the yeast cell cycle transcription factor SFF. Embo $J$. 19: $3750-3761$.

Quandt, K., Frech, K., Karas, H., Wingender, E., and Werner, T. 1995. MatInd and MatInspector: New fast and versatile tools for detection of consensus matches in nucleotide sequence data. Nucleic Acids Res. 23: 4878-4884.

Sandell, L.L. and Zakian, V.A. 1993. Loss of a yeast telomere: Arrest, recovery, and chromosome loss. Cell 75: 729-739.

Shimizu, M., Roth, S.Y., Szent-Gyorgyi, C., and Simpson, R.T. 1991. Nucleosomes are positioned with base pair precision adjacent to the alpha 2 operator in Saccharomyces cerevisiae. Embo J. 10: 3033-3041.

Simon, I., Barnett, J., Hannett, N., Harbison, C.T., Rinaldi, N.J., Volkert, T.L., Wyrick, J.J., Zeitlinger, J., Gifford, D.K., Jaakkola, T.S., et al. 2001. Serial regulation of transcriptional regulators in the yeast cell cycle. Cell 106: 697-708.

Stanbrough, M. and Magasanik, B. 1996. Two transcription factors, Gln3p and Nillp, use the same GATAAG sites to activate the expression of GAP1 of Saccharomyces cerevisiae. J. Bacteriol. 178: 2465-2468.

Strahl-Bolsinger, S., Hecht, A., Luo, K., and Grunstein, M. 1997. SIR2 and SIR4 interactions differ in core and extended telomeric heterochromatin in yeast. Genes \& Dev. 11: 83-93.

Strathern, J.N. 1989. Control and execution of mating type switching in Saccharomyces cerevisiae. American Society for Microbiology, Washington, D.C.

Szeto, L. and Broach, J.R. 1997. Role of alpha2 protein in donor locus selection during mating type interconversion. Mol. Cell. Biol. 17: 751-759.

Szeto, L., Fafalios, M.K., Zhong, H., Vershon, A.K., and Broach, J.R. 1997. Alpha2p controls donor preference during mating type interconversion in yeast by inactivating a recombinational enhancer of chromosome III. Genes \& Dev. 11: 18991911.

Tanaka, K., Oshima, T., Araki, H., Harashima, S., and Oshima, Y. 1984. Mating type control in Saccharomyces cerevisiae: A frameshift mutation at the common DNA sequence, $\mathrm{X}$, of the HML alpha locus. Mol. Cell. Biol. 4: 203-211.

Weiler, K.S. and Broach, J.R. 1992. Donor locus selection during Saccharomyces cerevisiae mating type interconversion responds to distant regulatory signals. Genetics 132: 929-942.

Weiler, K.S., Szeto, L., and Broach, J.R. 1995. Mutations affecting donor preference during mating type interconversion in Saccharomyces cerevisiae. Genetics 139: 1495-1510.

Weiss, K. and Simpson, R.T. 1997. Cell type-specific chromatin organization of the region that governs directionality of yeast mating type switching. Embo J. 16: 4352-4360.

Wu, C., Weiss, K., Yang, C., Harris, M.A., Tye, B.K., Newlon, C.S., Simpson, R.T., and Haber, J.E. 1998. Mcm1 regulates donor preference controlled by the recombination enhancer in Saccharomyces mating-type switching. Genes \& Dev. 12: 1726-1737.

Wu, X. and Haber, J.E. 1995. MATa donor preference in yeast mating-type switching: Activation of a large chromosomal region for recombination. Genes \& Dev. 9: 1922-1932.

. 1996. A 700 bp cis-acting region controls mating-type dependent recombination along the entire left arm of yeast chromosome III. Cell 87: 277-285.

Wu, X., Moore, J.K., and Haber, J.E. 1996. Mechanism of MAT alpha donor preference during mating-type switching of Saccharomyces cerevisiae. Mol. Cell. Biol. 16: 657-668.

Wu, X., Wu, C., and Haber, J.E. 1997. Rules of donor preference in Saccharomyces mating-type gene switching revealed by a competition assay involving two types of recombination. Genetics 147: 399-407.

Zhu, G., Muller, E.G., Amacher, S.L., Northrop, J.L., and Davis, T.N. 1993. A dosage-dependent suppressor of a temperaturesensitive calmodulin mutant encodes a protein related to the fork head family of DNA-binding proteins. Mol. Cell. Biol. 13: 1779-1787.

Zhu, G., Spellman, P.T., Volpe, T., Brown, P.O., Botstein, D., Davis, T.N., and Futcher, B. 2000. Two yeast forkhead genes regulate the cell cycle and pseudohyphal growth. Nature 406: $90-94$. 


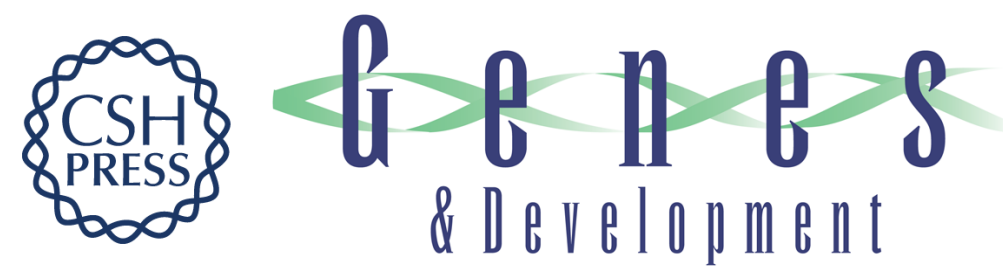

\section{Saccharomyces forkhead protein Fkh1 regulates donor preference during mating-type switching through the recombination enhancer}

Kaiming Sun, Eric Coi?c, Zhiqi Zhou, et al.

Genes Dev. 2002, 16:

Access the most recent version at doi:10.1101/gad.994902

References This article cites 38 articles, 20 of which can be accessed free at: http://genesdev.cshlp.org/content/16/16/2085.full.html\#ref-list-1

License

Email Alerting

Receive free email alerts when new articles cite this article - sign up in the box at the top Service right corner of the article or click here.

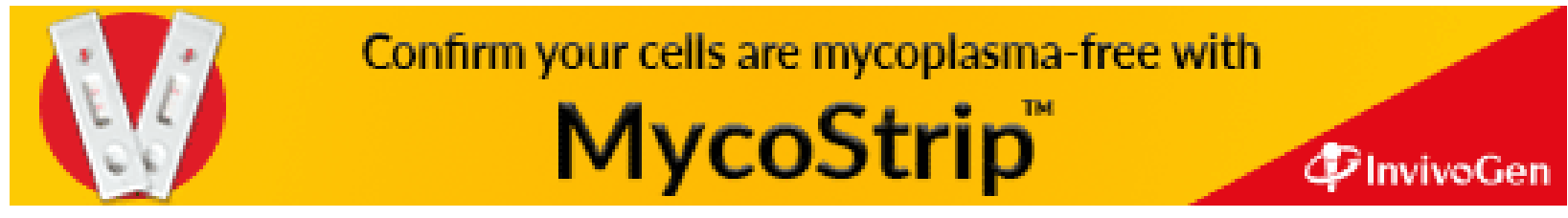

